Revista Brasileira de Agricultura Irrigada v.14, nº.4, p. 4171 - 4179, 2020

ISSN 1982-7679 (On-line)

Fortaleza, CE, INOVAGRI - http://www.inovagri.org.br

DOI: $10.7127 /$ rbai.v14n401189

Protocolo 1189.20 - 11/09/2020 Aprovado em 29/10/2020

\title{
VIABILIDADE ECONÔMICA DE IRRIGAÇÃO POR PIVÔ CENTRAL EM PEQUENAS ÁREAS CULTIVADAS COM FEIJÃO, SOJA E MILHO
}

\author{
Job Teixeira de Oliveira ${ }^{1}$, Reginaldo Miranda de Oliveira ${ }^{2}$, Rubens Alves de Oliveira ${ }^{3}$, Ednaldo \\ Miranda de Oliveira ${ }^{4}$, Margareth Evangelista Botelho ${ }^{5}$, Pedro Maurício Oliveira Ferreira ${ }^{6}$
}

\begin{abstract}
RESUMO
O uso de irrigação em culturas de ciclo curto pode propiciar ao produtor o plantio de várias culturas dentro de um mesmo ano-safra, contudo, os custos de implantação e operacional são variáveis de acordo com a área cultivada. O objetivo deste trabalho foi verificar a viabilidade econômica da irrigação por pivô central em pequenas áreas com cultivos de milho grão, feijão, soja e milho silagem. Para o estudo, considerou-se uma área irrigada por pivô central em pequenas áreas de 2,80 ha, simulando o cultivo rotativo de milho grão, feijão, soja e milho silagem, na região de CoimbraMG, ao longo da vida útil do sistema de 30 anos. Considerou-se a ET0 média histórica da região de 8 $\mathrm{mm}$ dia $^{-1}$ para dimensionamento dos projetos e manejo da irrigação. Foi realizado o cálculo de indicadores financeiros em função de coeficientes técnicos de cultivo para a região. De maneira geral, observa-se que, em média, 71,65\% dos custos totais de produção do sistema agrícola de milho grão, feijão, soja e milho silagem destinam-se ao preparo, plantio, tratos culturais e colheita, e apenas 23,50\%, à irrigação (investimento com equipamentos hidráulicos e infraestrutura, energia, depreciação e manutenção). As rentabilidades das safras do milho grão, feijão, soja e do milho silagem foram de $\mathrm{R} \$ 7.610,33, \mathrm{R} \$ 3.481,95, \mathrm{R} \$ 2.228,79$ e $\mathrm{R} \$ 20.457,22 \mathrm{ha}^{-1}$ ano $^{-1}$, respectivamente. A implantação de um sistema de irrigação por pivô central pequenas áreas é viável para o cultivo de milho em grão, feijão, soja e milho em silagem considerando um horizonte de 5 anos de retorno do investimento, nas condições do estudo.
\end{abstract}

Palavras-chave: Análise financeira, custo de produção, aspersão mecanizada

\footnotetext{
${ }^{1}$ Professor adjunto, Departamento de Engenharia Agrícola, Universidade Federal do Maranhão, Chapadinha - MA, Brasil, job.oliveira@hotmail.com

${ }^{2}$ Doutor, Departamento de Engenharia Agrícola e Ambiental, Universidade Federal de Viçosa, Viçosa - MG, Brasil, reginalo.miranda@ufv.br

${ }^{3}$ Professor titular, Departamento de Engenharia Agrícola e Ambiental, Universidade Federal de Viçosa, Viçosa - MG, Brasil, rubens@ufv.br

4 Doutor, Instituto Federal do Espírito Santo - Campus Santa Teresa, Santa Teresa - ES, Brasil, ednaldo.oliveira@ifes.edu.br

${ }_{6}^{5}$ Doutora, Departamento de Zootecnia, Universidade Federal de Viçosa, Viçosa - MG, Brasil, margareth.botelho@ufv.br 6 Graduando, Departamento de Agronomia, Universidade Federal de Viçosa, Viçosa - MG, Brasil, pedro.mauricio@ufv.br
} 


\title{
ECONOMIC FEASIBILITY OF CENTRAL PIVOT IRRIGATION SMALL AREAS IN THE BEAN, SOY AND CORN CROPS
}

\begin{abstract}
The use of irrigation in short-cycle crops can allow the producer to plant several crops within the same crop year, however, the costs of implementation and operation are variable according to the cultivated area. The objective of this work was to verify the economic viability of irrigation by mini central pivot in corn, bean, soybean and silage corn crops. In this study, we considered in area irrigated by a mini central pivot of $2.80 \mathrm{ha}$, simulating the rotational cultivation of corn grain, beans, soybeans and silage corn, in the region of Coimbra-MG, throughout the useful life of the 30 years. The historical average ET0 of the region of $8 \mathrm{~mm}$ day-1 was considered for project dimensioning and irrigation management. Financial indicators were calculated based in technical cultivation coefficients for the region. In general, we observed that, on average, $71.65 \%$ of the total production costs of the agricultural system of corn, beans, soybeans and silage corn are used for the preparation, planting, cultivation and harvesting, and only $23.50 \%$, to irrigation (investment in hydraulic equipment and infrastructure, energy, depreciation and maintenance). The yields for the grain, bean, soybean and silage corn crops were $\mathrm{R} \$ 7,610.33, \mathrm{R} \$ 3,481.95, \mathrm{R} \$ 2,228.79$ and $\mathrm{R} \$ 20,457.22$ ha-1 year-1, respectively. The implantation of an irrigation system by mini central pivot is feasible for the cultivation of corn in grain, beans, soy and corn in silage considering a horizon of 5 years of return on investment, under study conditions.
\end{abstract}

Keywords: Financial analysis, production cost, mechanized spraying

\section{INTRODUÇÃO}

Dentre os benefícios observados na prática da irrigação, destacam-se: aumento da produtividade da ordem de 2 a 3 vezes em relação à agricultura de sequeiro; redução do custo unitário de produção; utilização do solo durante todo $\mathrm{o}$ ano com até 3 (três) culturas/ano; utilização de mão-de-obra ao longo do ano; aumento na oferta de alimentos com regularidade ao longo do ano; atenuação do fator sazonalidade climática; viabilização da implantação de agroindústrias; maior qualidade e padronização dos produtos agrícolas; abertura e elevação da renda do produtor rural; modernização dos sistemas de produção, criação de polos agroindustriais para o aproveitamento da produção, entre outros benefícios (ANA, 2019)

Entre 1960 e 2015 a área irrigada no Brasil aumentou expressivamente, passando de 462 mil hectares para 6,95 milhões de hectares (Mha), e pode expandir mais $45 \%$ até 2030, atingindo 10 Mha, segundo o Atlas Irrigação (ANA, 2017).
A cultura de grãos é considerada de ciclo curto e, por isso, apresenta uma vantagem para o produtor, que consegue adequar o seu plantio dentro de uma janela menor, sem ter que abrir mão da produção de outros grãos ainda no mesmo ano-safra. Nesse cenário, o Brasil possui três épocas distintas de plantio, favorecendo assim uma oferta constante do produto ao longo do ano (CONAB, 2020).

Nesta temporada 2019/20, a produção de feijão está estimada em 3181,2 mil toneladas. Já a cultura da soja, a estimativa é que o país produza 120,9 milhões de toneladas, recorde histórico, representando um acréscimo de $5,1 \%$ em relação ao exercício passado. O milho considerando as três safras, a avaliação é de 102,1 milhões de toneladas produzidas, aumento de $2,1 \%$ em relação ao último exercício, e recorde na série histórica (CONAB, 2020).

Neste sentido, este trabalho objetivou verificar a viabilidade econômica da irrigação por pivô central pequenas áreas em cultivos de milho grão, feijão, soja e milho silagem. 


\section{MATERIAL E MÉTODOS}

Para o estudo de viabilidade econômica do cultivo de milho em grão com irrigação por pivô central pequenas áreas, foi realizado um experimento no período de janeiro a junho de 2017, na área experimental da Universidade Federal de Viçosa (UFV), município de Coimbra - MG. A área está situada a $20^{\circ} 49^{\prime}$ $51^{\prime \prime} \mathrm{S}$ e $42^{\circ} 48^{\prime} 10^{\prime \prime} \mathrm{O}$, com altitude de $716 \mathrm{~m}$. A cidade possui, segundo a classificação de Köppen, clima tropical de altitude (Cwb), com uma estação bastante chuvosa, principalmente nos meses de dezembro e janeiro, com média de precipitação de $1.300 \mathrm{~mm}$ e temperatura média anual de $19^{\circ} \mathrm{C}$.
O solo da área experimental é do tipo Argissolo Vermelho-Amarelo distrófico, argiloso/argiloso com relevo suave ondulado, caulinítico (PVAd) (EMBRAPA, 2018).

A caraterização físico-química do solo foi realizada em amostras coletadas na profundidade de 0 a $0,20 \quad \mathrm{~m} \quad \mathrm{e}$ analisadas nos Laboratório de Física do Solo do Departamento de Engenharia Agrícola (DEA) e Laboratório de Fertilidade do Solo do Departamento de Solos, respectivamente, ambos da Universidade Federal de Viçosa, sendo os resultados apresentados nas Tabelas 1 e 2 .

Tabela 1 - Características físico-hídricas do solo da área experimental

\begin{tabular}{|c|c|c|c|c|c|c|}
\hline \multirow{2}{*}{$\begin{array}{l}\text { Camada } \\
(\mathrm{cm})\end{array}$} & \multicolumn{3}{|c|}{ Distribuição granulométrica (\%) } & \multicolumn{2}{|c|}{ Teor de água $\left(\mathrm{g} \mathrm{g}^{-1}\right)$} & \multirow[t]{2}{*}{$\begin{array}{l}\text { Densidade do solo } \\
\left(\mathrm{g} \mathrm{cm}^{-3}\right)\end{array}$} \\
\hline & Argila & Silte & Areia grossa & $\mathrm{Cc}$ & $\mathrm{Pm}$ & \\
\hline $0-20$ & 58 & 18 & 24 & 0,335 & 0,180 & 1,3 \\
\hline
\end{tabular}

Tabela 2 - Características químicas do solo da área experimental

\begin{tabular}{|c|c|c|c|c|c|c|c|c|c|c|c|c|c|}
\hline \multirow{2}{*}{$\begin{array}{c}\text { Camada } \\
(\mathrm{cm})\end{array}$} & \multirow{2}{*}{$\begin{array}{r}\mathrm{pH} \\
\mathrm{H}_{2} \mathrm{O}\end{array}$} & $\mathrm{P}$ & $\mathrm{K}$ & $\mathrm{Ca}^{2+}$ & $\mathrm{Mg}^{2+}$ & $\mathrm{Al}^{3+}$ & $\mathrm{H}+\mathrm{Al}$ & SB & $\mathrm{t}$ & $\mathrm{T}$ & \multirow{2}{*}{$\begin{array}{l}\mathrm{V} \\
\%\end{array}$} & \multirow{2}{*}{$\begin{array}{l}\text { P-rem } \\
\mathrm{mg} \mathrm{L}^{-1}\end{array}$} & \multirow{2}{*}{$\begin{array}{c}\mathrm{MO} \\
\underset{1}{\operatorname{dag} \mathrm{kg}^{-}}\end{array}$} \\
\hline & & \multicolumn{2}{|c|}{$\mathrm{mg} \mathrm{dm}^{-3}$} & \multicolumn{7}{|c|}{$\mathrm{cmol}_{\mathrm{c}} \mathrm{dm}^{-3}$} & & & \\
\hline $0-20$ & 5,70 & 27,46 & 106,80 & 3,26 & 0,71 & 0,00 & 3,48 & 4,24 & 4,24 & 7,72 & 54,82 & 33,34 & 2,71 \\
\hline
\end{tabular}

P, Na, K - Extrator Mehlich - 1; Mat. Org. (MO) - C.org. x 1,724; T: CTC a pH 7,0; H+Al - acetato de cálcio 0,5; SB: Soma de bases; V: Saturação de bases; $\mathrm{Ca}, \mathrm{Mg}, \mathrm{Al}-\mathrm{KCl} 1 \mathrm{~mol} \mathrm{L-1;} \mathrm{t:} \mathrm{CTC} \mathrm{efetiva.}$

Foi realizada análise de viabilidade econômica por meio da simulação utilizandose a planilha eletrônica amazonSaf (ARCOVERDE; AMARO, 2011). Os custos de produção foram estimados utilizando-se valores aproximados em reais $(\mathrm{R} \$)$, considerando-se uma área cultivada de 2,80 ha, por meio da simulação do cultivo de três culturas em pivô central pequenas áreas dimensionadas com a lâmina de irrigação de $20 \mathrm{~mm} / \mathrm{dia}^{-1}$.

A lâmina de projeto foi calculada utilizando um coeficiente de cultura máximo de 1,1 , correspondente ao maior período de demanda hídrica da cultura do milho (ALLEN et al., 1998), cultura de maior demanda dentro do sistema de cultivo adotado (soja, milho grãos, milho silagem e feijão) e eficiência de aplicação de $85 \%$ para pivô central (BERNARDO et al., 2018).

Para o cálculo da lâmina adotada no manejo de irrigação de janeiro a maio (período de cultivo do milho segunda safra), utilizou-se um Kc médio de 1,10 para a cultura do milho. Consideraram-se 200 dias de irrigação por ano, sendo 60 dias de irrigação em cultivo de verão (milho em grão), 90 dias de irrigação em cultivo de outono/inverno (feijão/soja) e 50 dias de irrigação na cultura de inverno/primavera (soja), com ciclo médio de 120 dias tanto para o milho grão, quanto para o feijão e soja e 100 dias para o milho em silagem.

É caracterizado como pivô pequenas áreas, o equipamento do tipo pivô central, geralmente inferior a 10 ha e que possui uma 
tubulação aérea de 5" (cinco polegadas). Este equipamento é muito versátil e acessível ao pequeno produtor devido ao preço mais acessível e também às facilidades de financiamento na linha Pronaf - Mais Alimentos, do Governo Federal.

Para os cálculos foi projetado equipamento com área de 2,8 ha, com desnível de terreno de 2,0\%. A obtenção dos custos de implementação do projeto de irrigação e da infraestrutura de energia e transformadores foi realizada em estabelecimentos comerciais locais especializadas em irrigação. Além disto, os dados necessários para implementação da cultura foram obtidos com base no livro de referência nacional de custos de produção (AGRIANUAL, 2019).

Para cálculos de viabilidade, utilizou-se a metodologia apresentada em Alves Júnior et al. (2018).

Os indicadores que avaliaram a viabilidade do investimento foram o indicador de lucratividade, referente à receita bruta $(\mathrm{RE}$, $\mathrm{R} \$)$, que foi determinada pela Equação 1:

$R E=P R O \times P R E$

Em que PRO é a produção na área de estudo, 2,80 ha (kg), e PRE, o preço de venda (R\$).

$\mathrm{O}$ valor presente líquido (VPL) definido como a diferença entre o valor presente dos benefícios e o valor presente dos custos (FRIZZONE; ANDRADE JÚNIOR, 2005). O VPL foi determinado pela Equação 2:

$$
V P L=\sum_{j=0}^{I} \frac{F C_{j}}{(1+i)^{j}}
$$

Em que: ' $n$ ' a longevidade do projeto, ' $j$ ' o período, 'FC' o saldo do fluxo de caixa e 'i' a taxa de juros anual de $4 \%$;

A taxa interna de retorno (TIR) determinada pela Equação 3 é a potencialidade do projeto de gerar retornos (FRIZZONE; ANDRADE JUNIOR, 2005):

$$
T I R=\sum_{j=0}^{I} \frac{F C_{j}}{(1+i)^{j}}
$$

Período de recuperação (Pay back) é o tempo que o projeto leva para retornar o capital investido (NORONHA, 1987).

A razão benefício/custo $(\mathrm{B} / \mathrm{C})$ é utilizada para verificar se os benefícios são maiores do que os custos e é determinada de acordo com a Equação 4 (FRIZZONE; ANDRADE JÚNIOR, 2005):

$B / C=\frac{\sum_{k=o}^{I} B_{k}(1+j)^{-k}}{\sum_{k=o}^{I} C_{k}(1+j)^{-k}}$

Em que B é o benefício ( $\mathrm{R} \$), \mathrm{C}$, o custo $(\mathrm{R} \$)$, $\mathrm{j}$, a taxa de juros (anual) e $\mathrm{k}$, a vida útil (anos).

Os preços de venda do milho grão (produtividade $=12.420 \quad \mathrm{~kg} \cdot \mathrm{ha}^{-1} ; \quad$ preço $=\mathrm{R} \$ 0,49 \mathrm{~kg}^{-1}$ ), do feijão (produtividade $=$ $3.000 \mathrm{~kg} \cdot \mathrm{ha}^{-1}$; preço $\left.=\mathrm{R} \$ 1,75 \mathrm{~kg}^{-1}\right)$, da soja (produtividade $=3.120 \mathrm{~kg} \cdot \mathrm{ha}^{-1}$; preço $\left.=\mathrm{R} \$ 1,13 \mathrm{~kg}^{-1}\right)$ e do milho em silagem (produtividade $=168.000 \mathrm{~kg} \cdot \mathrm{ha}^{-1} ;$ preço $=\mathrm{R} \$$ $0,18 \mathrm{~kg}^{-1}$ ) representam os valores aceitos e utilizados pela AEB (2019), em projeções e financiamentos.

A Tabela 3 apresenta a época de plantio do milho em grão, feijão, soja e milho em silagem, em Coimbra (MG), com média de 3,0 safras por ano.

$\mathrm{Na}$ elaboração do projeto, foi preconizado o cultivo de milho grão no primeiro ano, sucedidos pela cultura do feijão e da soja, porém, no ano agrícola seguinte optou-se pela produção do milho silagem em substituição à soja e pela produção de milho em silagem na safra de verão.

Estas substituições foram realizadas visando melhorar a lucratividade uma vez que a soja irrigada apresenta baixa lucratividade. 
Tabela 3 - Época do ano de plantio do milho grão, feijão, soja e milho em silagem em Coimbra (MG), em pivô central pequenas áreas. Destaque para a média de 3,0 safras por ano, com total de 90 colheitas em 30 anos.

\begin{tabular}{cccc}
\hline ANO & JAN & MAI & SET \\
\hline 1 & Milho grão & Feijão & Soja \\
2 & Milho Silagem & Feijão & Milho Silagem \\
3 & Milho Silagem & Feijão & Milho grão \\
4 & Milho Silagem & Feijão & Milho grão \\
5 & Milho Silagem & Feijão & Milho grão \\
6 & Milho Silagem & Feijão & Milho grão \\
7 & Milho Silagem & Feijão & Milho grão \\
8 & Milho Silagem & Feijão & Milho grão \\
$\cdot$ & $\cdot$ & $\cdot$ & $\cdot$ \\
$\cdot$ & $\cdot$ & $\cdot$ & $\cdot$ \\
. & $\cdot$ & $\cdot$ & $\cdot$ \\
30 & Milho Silagem & Feijão & Milho grão \\
\hline
\end{tabular}

Na região de Coimbra-MG existe grande demanda por silagem de milho, portanto esta é uma opção rentável. Além do mais, o milho em silagem apresenta a vantagem de antecipação da colheita, possibilitando ainda a realização de contratos de vendas antecipados com um preço atrativo. O uso da silagem é uma boa recomendação para compensar a flutuação estacional no crescimento de pastos e uma maneira de tornar a produção pecuária menos dependente das condições climáticas.

A partir do terceiro ano agrícola optouse por cultivar milho em silagem, feijão e milho em grão, visando manter-se a competitividade do sistema produtivo, uma vez que com este sistema de safras seria possível fornecer ao mercado três produtos diferentes.

\section{RESULTADOS E DISCUSSÃO}

Os resultados das análises econômicas revelaram que, em ordem decrescente, os custos totais de produção para pivô central em pequenas áreas convencionais foram: feijão, milho em silagem, milho em grão e soja, em Coimbra, MG, com R\$ 4.340,91, R\$ 3.818,31, $\mathrm{R} \$ 3.712,99$ e R $\$ 3.268,46 \mathrm{ha}^{-1}$, respectivamente (Tabela 4$)$.

$O$ custo de produção do feijão foi de
1,13 vezes maior que o milho em silagem, 1,16 vezes o do milho em grão e 1,32 o da soja, em razão dos altos custos com preparo e plantio, que, juntos, representaram $20,50 \%$ dos custos.

Resultados encontrados por GERLACH et al. (2013) foram de $31,20 \%$ e $24,47 \%$ nos custos com insumos e operações mecanizadas, respectivamente, em cultivo do feijoeiro irrigado.

Já para o município de Unaí-MG, Fernandes (2012) obteve que as despesas com custeio da lavoura de feijão irrigada por pivô central representam $65,39 \%$ dos custos totais de produção, assemelhando muito do presente estudo onde foi observado que estas despesas representam cerca de $63,10 \%$.

Ao avaliar os custos de produção do milho em silagem irrigado por pivô central cultivado na região de Montes Claros-MG, Rabelo et al. (2017) obtiveram um custo de produção de $\mathrm{R} \$ 3.849,03 \mathrm{ha}^{-1}$, valor bastante similar ao apresentado na Tabela 4 .

$\mathrm{O}$ custo de implantação do sistema completo de irrigação por pivô central pequenas áreas foi de $\mathrm{R} \$ 46.285,71$ ha- 1 . Observa-se um elevado valor do custo de implantação do equipamento, além disto, quanto menor a área sob o pivô, maior é o custo de implementação do sistema (ANDRADE e ALBUQUERQUE, 2015). 
Tabela 4 - Porcentagem de investimentos, atividades e insumos no custo total de produção de milho em grão, feijão, soja e milho em silagem irrigados por pivô central pequenas áreas, em Coimbra, MG.

\begin{tabular}{|c|c|c|c|c|c|c|c|c|}
\hline \multirow{2}{*}{ Investimentos/atividades/insumos } & \multicolumn{2}{|c|}{ milho grão } & \multicolumn{2}{|c|}{ feijão } & \multicolumn{2}{|c|}{ Soja } & \multicolumn{2}{|c|}{ milho silagem } \\
\hline & $\mathrm{R} \$ \mathrm{ha}^{-1}$ & $\%$ & $\mathrm{R} \$ \mathrm{ha}^{-1}$ & $\%$ & $\mathrm{R} \$ \mathrm{ha}^{-1}$ & $\%$ & $\mathrm{R} \$ \mathrm{ha}^{-1}$ & $\%$ \\
\hline Custo de produção total & $3.712,99$ & 100,0 & $4.340,91$ & 100,0 & $3.268,46$ & 100,0 & $3.818,31$ & 100,0 \\
\hline Custo de oportunidade capital & 67,20 & 1,8 & 79,51 & 1,8 & 58,49 & 1,8 & 69,27 & 1,8 \\
\hline Depreciação & 285,71 & 7,7 & 285,71 & 6,6 & 285,71 & 8,7 & 285,71 & 7,5 \\
\hline Energia elétrica & 299,25 & 8,1 & 299,25 & 6,9 & 299,25 & 9,2 & 299,25 & 7,8 \\
\hline Manutenção & 228,57 & 6,2 & 228,57 & 5,3 & 228,57 & 7,0 & 228,57 & 6,0 \\
\hline Custos administrativos & 38,75 & 1,0 & 38,75 & 0,9 & 38,75 & 1,2 & 38,75 & 1,0 \\
\hline Impostos com Funrural & 134,34 & 3,6 & 115,72 & 2,7 & 82,28 & 2,5 & 237,60 & 6,2 \\
\hline Preparo e plantio & 257,77 & 6,9 & 892,00 & 20,5 & 341,19 & 10,4 & 257,77 & 6,8 \\
\hline Tratos culturais & $1.848,91$ & 49,8 & $1.848,91$ & 42,6 & $1.704,16$ & 52,1 & $1.848,91$ & 48,4 \\
\hline Colheita & 552,48 & 14,9 & 552,48 & 12,7 & 230,07 & 7,0 & 552,48 & 14,5 \\
\hline Totais pivô convencional & $3.712,99$ & 100,0 & $4.340,91$ & 100,0 & $3.268,46$ & 100,0 & $3.818,31$ & 100,0 \\
\hline
\end{tabular}

Assim, como as culturas apresentam custos de produção distintos, os custos de oportunidade do capital investido (sistema de irrigação e infraestrutura para implantação da irrigação) foram divididos igualmente para milho grão, feijão, soja e milho silagem que representaram $1,8 \%$ dos custos totais de produção de cada cultura, respectivamente (Tabela 4).

$\mathrm{Na}$ composição total do valor de investimento, foram considerados os valores de $\mathrm{R} \$ 4.000,00$ para construção da base do pivô, $\mathrm{R} \$ 5.000,00$ para a construção da casa de bombas e R\$ 600,00 para abertura e fechamento da valeta para colocação da adutora, R\$ 40.000,00 para infraestrutura elétrica composta de $1 \mathrm{~km}$ de rede de energia e transformador e também o valor do equipamento de pivô central para pequenas áreas convencionais de $\mathrm{R} \$ 80.000,00$. O valor total do projeto de pivô completo com 2,8 ha e todas as infraestruturas foi de R \$129.600,00.

Considerou-se o valor médio de $\mathrm{R} \$$ 0,25/KWh para energia (CEMIG, 2020). Foram considerados 360 dias de utilização da terra por ano, e para o cálculo da lâmina de irrigação, estes foram individuais para cada cultura, aplicada por ciclo.

Observa-se (Tabela 4) que, em média, $71,65 \%$ dos custos totais de produção do sistema agrícola de milho em grão, feijão, soja e milho em silagem destinam-se a preparo, plantio, tratos culturais e colheita, e apenas 23,5\%, à irrigação (investimento com equipamentos hidráulicos e infraestrutura, energia, depreciação e manutenção). A irrigação tem uma relação indireta com os custos de fertilizantes e defensivos, uma vez que a água aplicada em excesso pode causar lixiviação de nutrientes como nitrato e potássio bem como o surgimento de doenças e parasitas. O impacto negativo do excesso de água resulta em elevação dos custos de produção ou quebras de produtividade da lavoura, portanto os custos diretos e indiretos com irrigação podem representar mais de 1/4 dos custos de produção. Além das perdas de nutrientes no solo, teores elevados de água no solo, saturação, favorecem os microrganismos patogênicos (MAROUELLI et al., 2005; CARRER FILHO et al., 2009).

$\mathrm{Na}$ tabela 5, estão apresentados os indicadores econômicos do sistema de produção agrícola. 
Tabela 5 - Indicadores econômicos em trinta anos de investimento em sistemas de irrigação por pivô central pequenas áreas no cultivo do milho em grão, feijão, soja e milho em silagem, em Coimbra, MG.

\begin{tabular}{|c|c|c|c|c|c|}
\hline \multirow{3}{*}{ Atividade } & \multirow{3}{*}{$\begin{array}{l}\text { Receita } \\
\mathrm{R} \$ \mathrm{ha}^{-1}\end{array}$} & \multicolumn{3}{|c|}{ Lucro } & \multirow{3}{*}{$\begin{array}{l}\text { Avaliação } \\
\text { financeira }\end{array}$} \\
\hline & & Operacional & Liquido & Acumulado & \\
\hline & & $\mathrm{R} \$ \mathrm{ha}^{-1}$ & $\mathrm{R} \$ \mathrm{ha}^{-1}$ & $\mathrm{R} \$ \mathrm{ha}^{-1}$ & \\
\hline Safras ano 1 & $15.106,50$ & $3.989,34$ & $3.784,14$ & $3.784,14$ & \multirow{10}{*}{$\begin{array}{l}\text { Payback } \\
\text { 4,7 anos }\end{array}$} \\
\hline Safras ano 2 & $26.860,00$ & $15.100,52$ & $14.882,48$ & $18.666,62$ & \\
\hline Safras ano 3 & $22.166,50$ & $10.510,28$ & $10.294,30$ & $28.960,92$ & \\
\hline Safras ano 4 & $22.166,50$ & $10.510,28$ & $10.294,30$ & $39.255,22$ & \\
\hline Safras ano 5 & $22.166,50$ & $10.510,28$ & $10.294,30$ & $49.549,51$ & \\
\hline Safras ano 6 & $22.166,50$ & $10.510,28$ & $10.294,30$ & $59.843,81$ & \\
\hline . & . & . & . & . & \\
\hline . & . & . & . & . & \\
\hline . & . & . & . & . & \\
\hline Safra ano 30 & $22.166,50$ & $10.510,28$ & $10.294,30$ & $306.907,01$ & \\
\hline
\end{tabular}

Analisando a Tabela 5, verificamos que o lucro líquido acumulado com equipamento de pivô central pequenas áreas convencionais demoram quatro anos e oito meses para zerar o fluxo de caixa, ou seja, este seria o tempo necessário para zerar o investimento inicial considerando o ciclo de safras propostos nesta avaliação. Tal fato revela viabilidade do empreendimento menor que um horizonte de 5 anos (Tabela 6). A rentabilidade (VPL) das safras do milho em grão, feijão, soja e do milho em silagem foram de $\mathrm{R} \$ 7.610,33$, $\mathrm{R} \$$ $3.481,95, \mathrm{R} \$ 2.228,79$ e $\mathrm{R} \$ 20.457,22 \mathrm{ha}^{-1}$ ano $^{-1}$, respectivamente. Esses valores observados para a cultura do feijão são superiores aos R\$1.154,23 encontrados por Fernandes (2012) no cultivo do feijoeiro irrigado, no Noroeste mineiro.

Tabela 6 - Indicadores econômicos do sistema de irrigação por pivô central pequenas áreas nas safras de milho grão, feijão, soja e milho silagem na região de Coimbra, MG.

\begin{tabular}{ccccccc}
\hline \multirow{2}{*}{ Ano Safra } & Agrícola & Rentabilidade & Lucratividade & $\begin{array}{c}\text { Margem de } \\
\text { Contribuição }\end{array}$ & $\begin{array}{c}\text { Taxa de } \\
\text { Retorno }\end{array}$ & B/C \\
\hline \multirow{2}{*}{1} & Milho grão & $64,46 \%$ & $39,20 \%$ & $\mathrm{R} \$ 7.610,33$ & $67,49 \%$ & 1,67 \\
& Feijão & $21,17 \%$ & $17,47 \%$ & $\mathrm{R} \$ 3.481,95$ & $23,43 \%$ & 1,23 \\
& Soja & $14,43 \%$ & $12,61 \%$ & $\mathrm{R} \$ 2.228,79$ & $16,51 \%$ & 1,17 \\
\hline \multirow{2}{*}{2} & Milho silagem & $182,85 \%$ & $64,65 \%$ & $\mathrm{R} \$ 20.457,22$ & $188,07 \%$ & 2,88 \\
& Feijão & $21,17 \%$ & $17,47 \%$ & $\mathrm{R} \$ 3.481,95$ & $23,43 \%$ & 1,23 \\
& Milho silagem & $182,85 \%$ & $64,65 \%$ & $\mathrm{R} \$ 18.640,25$ & $188,07 \%$ & 2,88 \\
\hline \multirow{2}{*}{3} & Milho silagem & $182,85 \%$ & $64,65 \%$ & $\mathrm{R} \$ 20.457,22$ & $188,07 \%$ & 2,88 \\
& Feijão & $21,17 \%$ & $17,47 \%$ & $\mathrm{R} \$ 3.481,95$ & $23,43 \%$ & 1,23 \\
& Milho grão & $64,46 \%$ & $39,20 \%$ & $\mathrm{R} \$ 7.610,33$ & $67,49 \%$ & 1,67 \\
\hline \multirow{2}{*}{4} & Milho silagem & $182,85 \%$ & $64,65 \%$ & $\mathrm{R} \$ 20.457,22$ & $188,07 \%$ & 2,88 \\
& Feijão & $21,17 \%$ & $17,47 \%$ & $\mathrm{R} \$ 3.481,95$ & $23,43 \%$ & 1,23 \\
& Milho grão & $64,46 \%$ & $39,20 \%$ & $\mathrm{R} \$ 7.610,33$ & $67,49 \%$ & 1,67 \\
\hline
\end{tabular}

Para as quatro culturas avaliadas (Tabela 6), verificou-se lucro indicado por $\mathrm{B} / \mathrm{C}>1,0$ (GARZEL, 2003), assim como a cada ano de cultivo (Tabela 7). O primeiro ano apresentou o menor lucro (R $\$ 0,21)$, devido principalmente à baixa lucratividade da soja irrigada, por outro lado, devido à realização de duas safras de milho silagem no segundo ano, 
este foi o que apresentou maior lucratividade (R\$ 1,33).

A cultura do feijão apresentou uma razão benefício/custo $(\mathrm{B} / \mathrm{C})$ de 1,23 , valor menor que o 1,32 observado por Fernandes (2012) ao realizar um estudo de viabilidade, em Unaí-MG. Esta diferença possivelmente se deve aos contrastes edafoclimáticas das regiões da Zona da Mata e do Noroeste Mineiro e também porque os equipamentos de irrigação utilizados são maiores e há uma maior diluição do custo de investimento, comparado com o equipamento utilizado neste estudo.

Tabela 7 - Indicadores econômicos anuais do investimento em sistemas de irrigação por pivô central pequenas áreas no cultivo do milho em grão, feijão, soja e milho em silagem, na região de Coimbra, MG.

\begin{tabular}{cccccc}
\hline Atividade & Rentabilidade & Lucratividade & Margem de & Taxa de Retorno & B/C \\
Agrícola & $\%$ & $\%$ & Contribuição (VPL) & $\%$ & $\mathrm{R} \$$ \\
\hline Ano Safra 1 & $33,35 \%$ & $23,09 \%$ & $\mathrm{R} \$ 4.440,35$ & $35,81 \%$ & 1,21 \\
Ano Safra 2 & $128,96 \%$ & $48,92 \%$ & $\mathrm{R} \$ 14.193,14$ & $133,19 \%$ & 2,33 \\
Ano Safra 3 & $89,49 \%$ & $40,44 \%$ & $\mathrm{R} \$ 10.516,50$ & $93,00 \%$ & 1,78 \\
Ano Safra 4 & $89,49 \%$ & $40,44 \%$ & $\mathrm{R} \$ 10.516,50$ & $93,00 \%$ & 1,78 \\
$\cdot$ & $\cdot$ & $\cdot$ & $\cdot$ & $\cdot$ & $\cdot$ \\
$\cdot$ & $\cdot$ & $\cdot$ & $\cdot$ & $\cdot$ & $\cdot$ \\
. &. & $\cdot$ & $\cdot$ & $\cdot$ & $\cdot$ \\
Ano Safra 30 & $89,49 \%$ & $40,44 \%$ & $\mathrm{R} \$ 10.516,50$ & $93,00 \%$ & 1,78 \\
\hline
\end{tabular}

Ainda considerando as quatro culturas, pode-se verificar menor taxa de retorno (TIR) no cultivo da soja $(16,51 \%)$ e maior taxa de retorno no cultivo do milho em silagem $(188,07 \%)$. Nos dois primeiros anos, foram verificados TIR de $35,81 \%, 133,19 \%$ e a partir do terceiro, 93,00\% (Tabela 7). Considerando que um pivô central para pequenas áreas bem manejado em média tem longevidade superior a 30 anos e que no sistema adotado o produtor consegue abater os custos de implantação do pivô com menos de cinco anos, pode-se dizer que a partir do quinto ano de cultivo, neste sistema, a lucratividade é máxima.

\section{CONCLUSÃO}

A implantação de um sistema de irrigação por pivô central pequenas áreas é viável para o cultivo de milho grão, feijão, soja e milho em silagem considerando um horizonte de 5 anos de retorno do investimento, nas condições do estudo.

\section{REFERÊNCIAS}

Agência Nacional de Águas (Brasil). Levantamento da agricultura irrigada por pivôs centrais no Brasil. Agência Nacional de Águas, Embrapa Milho e Sorgo. 2. ed. Brasília: ANA, 2019. p. 47. ISBN: 978-858210-060-8.

Agência Nacional de Águas (Brasil). Atlas irrigação: uso da água na agricultura irrigada. Agência Nacional de Águas. Brasília: ANA, 2017. p. 86. ISBN 978-85-8210-051-6.

ARCO-VERDE, M. F.; AMARO, G. Cálculo de Indicadores Financeiros para Sistemas Agroflorestais. Boa Vista, RR. Documentos. Embrapa Roraima, 2011. v. 44. p. 1- 48.

Levantamento de preços de comodities. Associação de Comércio Exterior do Brasil (AEB), 2019. Disponível em < http://aeb.org.br/>. Acesso em: 21 de fev. de 2019. 
AGRIANUAL. Anuário da agricultura Brasileira. FNP: Consultoria Andamp. São Paulo, 2019. Comércio: p. 497.

ALLEN, R. G.; PEREIRA, L. S.; RAES, D.; SMITH, M. Crop evapotranspiration: Guidelines for computing crop water requirements. FAO - Irrigation and Drainage Paper, v. 56. p. 300, 1998.

ALVES JÚNIOR, J.; SALES, D. L. A.; PEREIRA, R. M.; RODRIGUEZ, W. D. M.; CASAROLI, D.; EVANGELISTA, A. W. P. Viabilidade econômica da irrigação por pivô central nas culturas de soja, milho e tomate. Pesquisa Agropecuária Pernambucana, v. 22. p. e201703, 2018.

ANDRADE, C.L.T.; ALBUQUERQUE, P.E.P. Manejo da irrigação. In: Borém, A.; Galvão, J.C.C; Pimentel, M.A. (Org.). ed. 1. Viçosa: UFV, 2015. Milho - Do Plantio à Colheita. v. 1. p. 178-206.

BERNARDO, S.; SOARES, A. A.; MANTOVANI, E. C. Manual de irrigação. 9. ed. Viçosa: UFV, 2018.

CARRER FILHO, R. et al. Potencialidade de um actinomiceto de rizosfera de tomateiro como agente de biocontrole de doenças. Horticultura Brasileira, 2009. v. 27. n. 3. p. 340-344.

CEMIG - Companhia de Energética de Minas Gerais - Valores de Tarifas e Serviços. 2020.

Disponível

em: https://novoportal.cemig.com.br/atendimento/ valores-de-tarifas-e-servicos/.

Companhia Nacional de Abastecimento (Conab). Acomp. safra bras. grãos, v. 7 Safra 2019/20 - Décimo primeiro levantamento, 2020. n. 11, p. 1-62.
EMBRAPA. Centro Nacional de Pesquisa de Solos. Manual de métodos de análise de solo. ed. 3. 2018.

FERNANDES, M.L. Retorno financeiro e risco de preço da cultura do feijão irrigado via pivô central na região Noroeste de Minas Gerais. Informações Econômicas, 2012. v. 42. n. 1. p. 41-53.

FRIZZONE, J. A.; ANDRADE JÚNIOR, A. S. Planejamento de irrigação: análise de decisão de investimento. Brasília: Embrapa Informação Tecnológica; Teresina: Embrapa Meio Norte, 2005. p. 626. ISBN: 85-7383308-4.

GARZEL, J. C. Matemática financeira e análise de investimentos. Curitiba: SENARPR, 2003. p. 37.

GERLACH, G. A. X.; ARF, O.; CORSINI, D. C. D. C.; SILVA, J. C.; COLETTI, A. J. Análise econômica da produção de feijão em função de doses de nitrogênio e coberturas vegetais. Pesquisa Agropecuária Tropical, 2013. v. 43. n. 1. p. 42-49.

MAROUELLI, W. A.; LOPES, C. A.; SILVA, W. L. C. Incidência de murcha-bacteriana em tomate para processamento industrial sob irrigação por gotejamento e aspersão. Horticultura Brasileira, 2005. v. 23. n. 2. p. 320-323.

RABELO, C. G.; SOUZA, L. H.; OLIVEIRA, F. G. Análise dos custos de produção de silagem de milho: estudo de caso. Caderno de Ciências Agrárias, 2017. v. 9. n. 2. p. 8-15. 